\title{
Theoretical study of the effect of round straps on the selectivity in a diamond mesh cod-end
}

\author{
Bent Herrmann ${ }^{\underline{a}}$, Daniel Priour ${ }^{\underline{b}}$ and Ludvig A. Krag ${ }^{\underline{a}}$
}

\begin{abstract}
${ }^{a}$ DIFRES, Danish Institute for Fisheries Research, North Sea Centre, DK-9850 Hirtshals, Denmark
IFREMER, French Institute for Research and Exploitation of the Sea, BP 7029280 Plouzane, France

Corresponding author : bhe@dfu.min.dk
\end{abstract}

\begin{abstract}
:
FEMNET, a numerical tool based on the finite element method, was applied to estimate the shapes of various diamond-mesh cod-end designs during fishing. The only design differences rest in the use of round straps of different lengths, positions and numbers. The cod-end shape estimates were then entered in the selectivity simulation tool PRESEMO to simulate the selectivity processes of the various cod-end designs under the same varying fishing conditions. This enabled us to demonstrate how one or two round straps along the cod-end axis may change the selectivity of the cod-end compared with a reference cod-end, without round straps. We predict that in cod-end designs, which comply with the EU legislation, the $50 \%$ retention length (L50) may be reduced by up to $1.5 \mathrm{~cm}(5 \%)$ for haddock
\end{abstract}

Keywords: Cod-end selectivity; Round straps; PRESEMO; FEMNET; Catch weight 


\section{Introduction}

\subsection{Introductory considerations}

According to the current EU legislation, a cod-end in a towed fishing gear must have a minimum mesh size. This mesh size is meant to allow fish under the minimum landing size to escape through the meshes. The ability of a cod-end to release undersized fish depends on the mesh opening. Underwater observations of diamond mesh cod-ends during trawl fishing have shown that these are distorted into a bulbous shape by water pressure acting on the accumulated catch (Stewart and Robertson, 1985). Most of the netting in front of the bulge is stretched and the mesh opening reduced. Only the meshes a few rows just ahead of the catch accumulation are open and unobstructed during a tow. It is mainly through these meshes that undersized fish escape (Stewart and Robertson, 1985; Wileman et al., 1996). Fishermen attach various devices to cod-ends to simplify handling and to reduce damage by wear. These secondary devices may affect the mesh opening in the cod-end and thereby the selectivity of the gear. The legislation concerning the use of these devices is given in the EU Regulation no. 3440/84.

\subsection{Round straps}

One of the secondary devices is the round strap. Round straps are ropes fitted around the cod-end, typically shorter than the stretched length of the cod-end circumference. One or more round straps are placed along the cod-end axis. According to EU Regulation no. 3440/84, their length must not be less than $40 \%$ of the cod-end stretched circumference. The minimum distance between two round straps must not be less than $1.0 \mathrm{~m}$, measured when the netting is stretched along the cod-end axis. The round straps are threaded through the meshes of a specific mesh row and then both ends of the straps are joined. Round straps restrict the diameter of the cod-end, dividing the catch into parts of a size convenient for handling aboard the vessel.

\subsection{Problem}

As far as we know, the legislation on round straps is based on limited scientific analysis. The problem was addressed in Stewart and Robertson (1985), but several questions arise from the use of round straps in cod-ends: Why is the strap length limit set to $40 \%$ in the EU legislation? What would happen if it was reduced to $30 \%$ or increased to $50 \%$ as in the Norwegian Regulation Jnotification no. 178-2005? What would happen if a strap was placed at different distances from the cod-line? Why is the distance between two successive straps so important? How dependent is the round strap effect on catch size? The objective of this paper is to answer these questions.

\subsection{Solutions proposed}

A solution could be to conduct extensive sea trials to cover all the round straps position and length configurations. Such trials are very resource demanding, and instead we propose to use the computer-based cod-end selectivity simulation program PRESEMO. The program implements an individual based structural model described in Herrmann (2005), which simulates the most important physical and biological selection processes in a diamond mesh cod-end of a towed fishing gear. PRESEMO requires information about the shape of the cod-end and how this shape is influenced by the volume (weight) of the catch. To estimate the shapes of cod-ends without round strap and with one or two of them of various lengths we used FEMNET, a simulation tool described in Priour (1999; 2001; 2005). FEMNET estimates the shape of flexible structures made of cables and nettings, such as towed trawls. Figure 1 shows how a round strap prevents the cod-end from attaining its typically bulbous shape while towed. The top picture was extracted from an underwater video recording whereas the bottom picture shows a cod-end in a similar situation simulated by FEMNET and PRESEMO. 


\section{Materials and methods}

\subsection{Cod-end designs}

The basic cod-end design used in this simulation study had $100 \mathrm{~mm}$ (inner measurement) diamond meshes made of $4 \mathrm{~mm}$ PE double twine. It was 50 meshes long with 100 open meshes around the circumference (table 1). Based on this basic cod-end a number of designs were investigated having no strap (reference cod-end), or incorporating one or two round straps of different lengths. Table 2 lists the details of the various designs and the name they were each assigned, for example 8_40 stands for a cod-end with one round strap threaded through the 8th mesh rows from the cod-line and with a length equivalent to $40 \%$ of the stretched cod-end circumference. For designs with two round straps a similar notation is used. For example 8_12_40 stands for a cod-end design with a round strap threaded through both the 8th and 12th mesh rows each with a length equivalent to $40 \%$ of the stretched cod-end circumference.

\subsection{Calculation of cod-end shapes}

Estimates of the cod-end shapes were calculated with FEMNET for each cod-end design listed in Table 2 for 12 catch weights: 19, 30, 47, 72, 112, 175, 272, 424, 661, 1029, 1604, $2500 \mathrm{~kg}$. The towing speed was assumed to be 3 knots. Since the results are uncertain for very small catch weights, the shape was assumed to be constant below a $19 \mathrm{~kg}$ catch weight. The tension in the round straps was also calculated with FEMNET, since only when the round strap is in tension does it affect the cod-end shape.

\subsection{Simulation of selection}

PRESEMO requires information on the fish behaviour, escape process, fish population structure, and fish morphology. Herrmann and O'Neill (2005) outlined a protocol for using PRESEMO where between-haul variation is taken into account. They used the protocol to study the selectivity of haddock for catch weights up to $500 \mathrm{~kg}$. In this study we followed the same sequence though we had to change some of the parameter values as we wanted to cover catch weights up to $1000 \mathrm{~kg}$. Therefore, we increased the range for the number of fish entering the cod-end during a simulated fishing process, both for the target and by-catch populations. Towing time was also increased to avoid too dense an entry of fish. Tables 3 and 4 list the fish data and other PRESEMO settings used in the simulations. For each cod-end design 1000 hauls were simulated which yielded 1000 estimates of the $50 \%$ retention length L50 and the selection range SR. SR is the difference in length between the fish that has a $75 \%$ probability of retention and that with a $25 \%$ probability of retention. The mesh row through which the round strap is threaded is partly blocked by the strap. The effect of this on fish escapement was assumed to be negligible and thus was not taken into account. Only the deformation of the cod-end shape caused by the round strap and its influence on the mesh opening was considered in the simulation of selection.

\section{Results}

\subsection{Shape calculations}

Only results for the cod-end designs marked with * in table 2, including the reference cod-end, are used and discussed below. Regarding the cod-ends of the unmarked designs the round straps never tightened enough to have an effect and thus the shapes were identical to those of the reference codend. Figure 2 shows screen dumps from PRESEMO with different simulated catch weights. The rows show for each cod-end design the different shapes corresponding to the different catch weights, demonstrating how tension in the round straps restricts the deformation caused by the catch. Table 5 lists the catch weights up to which the shape of the cod-ends fitted with only one 
round strap remains unaffected. Table 6 lists the catch weight up to which the shape of the cod-ends fitted with two round straps (designs 8_12_40, 8_17_40 and 8_21_40) is unaffected by the second strap.

\subsection{Selectivity simulations.}

In Figure 3 L50 is plotted versus the total catch weight for each of the 1000 simulated hauls for each design. The grey curves are the plots of the second-order polynomial regression of L50 versus the total catch weight. All plots show the same tendency: L50 increases monotonously with total catch weight. Figure 4 shows similar plots of SR versus total catch weight. No overall pattern is apparent, both increasing and decreasing tendencies are predicted. The selection parameters (L50 and SR) predicted by the regressions for the different cod-end designs are summarized and compared in Table 7. Several effects that round straps can have on the selection of round-fish in the cod-end and their dependency on catch weight are shown in Figure 5; furthermore, the regression results for L50 and SR against catch weight (column 2 and 3) for the different cod-end designs are plotted and compared with the corresponding results for the reference cod-end. Because most of the escapes of round fish occur within a few mesh rows just ahead of the catch (Stewart and Robertson, 1985; Wileman et al., 1996) the circumferential mesh opening here and its development during the catch accumulation is important for the selective properties for the different designs. The predictions by PRESEMO of the circumferential mesh opening at the edge of catch are therefore plotted in column 1 in figure 5.

\section{3 effect of length of round strap on L50}

By comparing the results for designs 6_20,6_30, with those of the reference cod-end (shapes identical to those of the 6_40,6_50 and 6_60) it may be deduced from table 7 and figure 5 that: a shorter strap leads to a lower L50. A strap attached as close as 6 mesh rows from the cod-line has a high effect at low catch weights. For a $200 \mathrm{~kg}$ catch L50 is reduced by $8 \%(2.1 \mathrm{~cm})$ for the 6_20 design. For a $1000 \mathrm{~kg}$ catch L50 is only reduced by $3 \%(0.7 \mathrm{~cm})$. This difference can be explained by the fact that at low catch weights the mesh opening at the catch edge is small for the 6_20 codend compared with that of the other cod-ends (figure 5, plot A). For larger catches the mesh opening increases towards the values of the 6_30 cod-end. The difference in mesh openings between the 6_20 and the reference cod-ends also decreases as the catch weight increases (figure 5, plot B). The shape plots in figure 2 also show that the effect of a round strap placed very close to the cod-line has a higher effect at small catch weights. For larger catches the catch accumulation edge has simply passed far beyond the strap thus reducing its overall effect. It should be noted that a strap placed as close as 6 meshes from the cod-line must be very short (below $40 \%$ ) to have any effect because the bulb of the cod-end is already restricted by the closed cod-line. The results for designs 8_30, 8_40 and the reference shows a similar tendency as above, the strap being placed a little further away from the cod-line. But in this case even a strap with a $40 \%$ length can affect the selection process. L50 is reduced by $0.4 \mathrm{~cm}$ in comparison with the reference cod-end for a $1000 \mathrm{~kg}$ catch weight, while for small catch weights the mesh opening for 8 40 is rather similar to that of the reference cod-end (figure 5 plot D). By increasing the total catch, the round strap under consideration starts prevent the cod-end diameter from expanding further. The mesh opening is thereby restricted which in turn will affect L50 (figure 5 plot E). The plots in figure 2, which compares the reference cod-end with the 8_40, show that the shapes for low catch weights (100 kg) are similar, whereas for larger catch weights $(500 \mathrm{~kg})$ the effect of the round strap is noticeable. The round strap has no effect at catch weights below $272 \mathrm{~kg}$ (table 5). Therefore, the minimum length a round strap can have without affecting the cod-end selection process will depend on how far the strap is placed from the cod-line. The importance of the position dependence of the round strap 
minimum length is, in contrast to the EU Regulation no. 3440/84, recognised by the Norwegian Regulation J-notification no.178-2005.

\subsection{The effect of the round strap position on L50}

In this section the use of a single round strap (40\%) placed at different mesh rows from the cod-line is investigated by comparing the results predicted for cod-end designs 6_40 (shapes equal to the reference design), 8_40,10_40 and 19_40. For catch weights up to $1000 \mathrm{~kg}$ the largest effect is found for the 10_40 cod-end with a 5\% reduction of L50 $(1.5 \mathrm{~cm})$ relative to the reference cod-end. When the strap is placed close to the cod-line its restricting effect is low since the opening of meshes near the cod-line is already restricted (figure 5, plot d). For a round strap placed far from the cod-line a large catch has to build up before any effect appears. Since the effect of L50 is an accumulative effect of the entire fishing process, the effect on the catch is delayed relative to the effect on the mesh opening. With the 19_40 design the catch effect is delayed to such an extent that its effect on L50, in the range of the catch weights investigated, is not noticeable.

\subsection{The effect of two round straps on L50}

This section is dedicated to the analysis of the effect of two round straps with a $40 \%$ length. The following cod-end designs were investigated: 8_12_40, 8_17_40, 8_21_40. Plots G, H and I in figure 5 show the results in comparison with the reference results. Summary results are also provided in table 7 . The mesh opening for all three designs is similar to that of the reference codend for catch weights below $272 \mathrm{~kg}$ (table 5; figure 5, plot G); for catch weights above 272, 424 and $661 \mathrm{~kg}$, corresponding to 8_12_40,8_17_40, 8_21_40, respectively, the second strap also begins to restrict the mesh opening (table 6). Considering a $1000 \mathrm{~kg}$ catch weight L50 is reduced by $6 \%$ (2.0 $\mathrm{cm})$ for the 8_12_40 cod-end compared to the reference cod-end and by 5\% $(1.6 \mathrm{~cm})$ compared to the 8 _40 cod-end (figure 5, plot $\mathrm{H}$ ). The mesh openings tend to be reduced both for the 8_17_40 and the 8_21_40 cod-end considering larger catch weights, (figure 5, plot G), trends which are also reflected in the respective L50 values. These results clearly demonstrate that the position of the second round strap can also affect the cod-end selection.

\subsection{The effect of round straps on $S R$}

Our results indicate that the introduction of round straps into the cod-end design generally tends to decrease the SR (table 7 and figure 5 plots C, F and I). This can be explained by the influence they have on the mesh opening at the edge of the catch by keeping it more constant during the fishing process (figure 5 plots A, D and G). This leads to less variable fish escape conditions. The only exception concerns the 6_20 design where SR is larger than for the reference cod-end consistent with a larger variation of mesh opening than for the reference cod-end.

\section{Discussion}

The use of simulation tools FEMNET and PRESEMO enabled us to conduct a theoretical investigation on the expected effect on haddock selection when introducing one or two round straps in the cod-end design. This case study relies on haddock, but we expect similar results for other round-fish species. Our reference cod-end design is similar to the one studied experimentally in O’Neill and Kynoch (1996) and theoretically in Herrmann and O’Neill (2005). These works provide results on haddock selection for a total catch weight not exceeding $500 \mathrm{~kg}$. They both found L50 has a tendency to increase along with the total catch weight. The mean values of the selection parameters were 28.6 - $28.7 \mathrm{~cm}$ (L50) and 5.1 - $5.3 \mathrm{~cm}$ (SR). For the reference cod-end we found that L50 had a tendency to increase along with the total catch weight (Fig. 3). For a $400 \mathrm{~kg}$ catch weight the mean values we found for the selection parameters are $28.8 \mathrm{~cm}$ (L50) and $5.0 \mathrm{~cm}$ (SR) 
(Table 7). Our selectivity predictions for the reference cod-end are therefore in reasonable agreement with the results reported by O’Neill and Kynoch (1996) and by Herrmann and O’Neill (2005).

The simulation methods described here have obvious advantages in comparison with experimental fishing. It is possible to run a very large number of hauls under varying fishing conditions, where each configuration is exposed to identical varying conditions, thus making explicit results comparable. We are also able to compare a large number of different cod-end designs. In this study we have investigated the effect of round straps for total catch weights in the range of 200 to 1000 kg. For larger catch weights it is possible that the effect on selectivity will increase even more for some of the designs. We predict that for cod-ends with round straps complying with the current EU legislation reductions in L50 reaching $5 \%(1.5 \mathrm{~cm})$ may occur. This study demonstrates that the effects round straps may have on the selection process are complex as they depend on both positions and lengths of the straps and catch weight. The legislation for deployment of round straps should therefore be based on results provided by detailed studies. In order to confirm these theoretical results a limited experimental study, including the reference cod-end and one or more designs incorporating round straps, could be conducted. Our study has shown that the effect of round straps on selectivity is not necessary negative. There is a tendency towards a reduced SR due to the mesh opening being more constant while fishing.

\section{Acknowledgement}

This study was carried out with the financial support from the Commission of the European Communities, specific RTD programme Quality of Life and Management of Living Resources, "PREMECS II: Development of predictive model of cod-end selectivity". It does not necessarily reflect the Commission's view and in no way anticipates its future policy in this area. Financial support was also given from project SELTRA financed by the Directorate for Food, Fisheries and Agri Business. The authors acknowledge B. Lundgren (DFIRES), P. Barthélemy (IFREMER) and the Editor of the journal for their invaluable help in improving the writing of this paper. The authors also acknowledge the great debt they owe their partners in the EU project PREMECS II. 


\section{References}

Herrmann, B., 2005. Effect of catch size and shape on the selectivity of diamond mesh cod-ends I. Model development. Fish. Res. 71, 1-13.

Herrmann, B. and O’Neill, F.G., 2005. Theoretical study of the between-haul variation of haddock selectivity in a diamond mesh cod-end. Fish. Res. 74, 243-252.

Priour, D., 1999. Calculation of net shapes by the finite element method with triangular elements. Commun. Numer. Meth. 15, 755-763.

Priour, D., 2001. Introduction of mesh resistance to opening in a triangular element for calculation of nets by the finite element method. Commun. Numer. Meth. 17, 229-237.

Priour, D., 2005. FEM modelling of flexible structures made of cables, bars and nets. IMAM 2005, Lisbon, ISBN 0415390362.

Stewart, P. A. M. and Robertson, J. H. B., 1985. Scottish Fisheries Research Report No. 33, 15 pp.

Wileman, D., Ferro, R. S. T., Fonteyne, R., Millar, R. B. (editors), 1996. Manual of methods of measuring the selectivity of towed fishing gears. ICES Coop. Res. Rep. No. 215. 

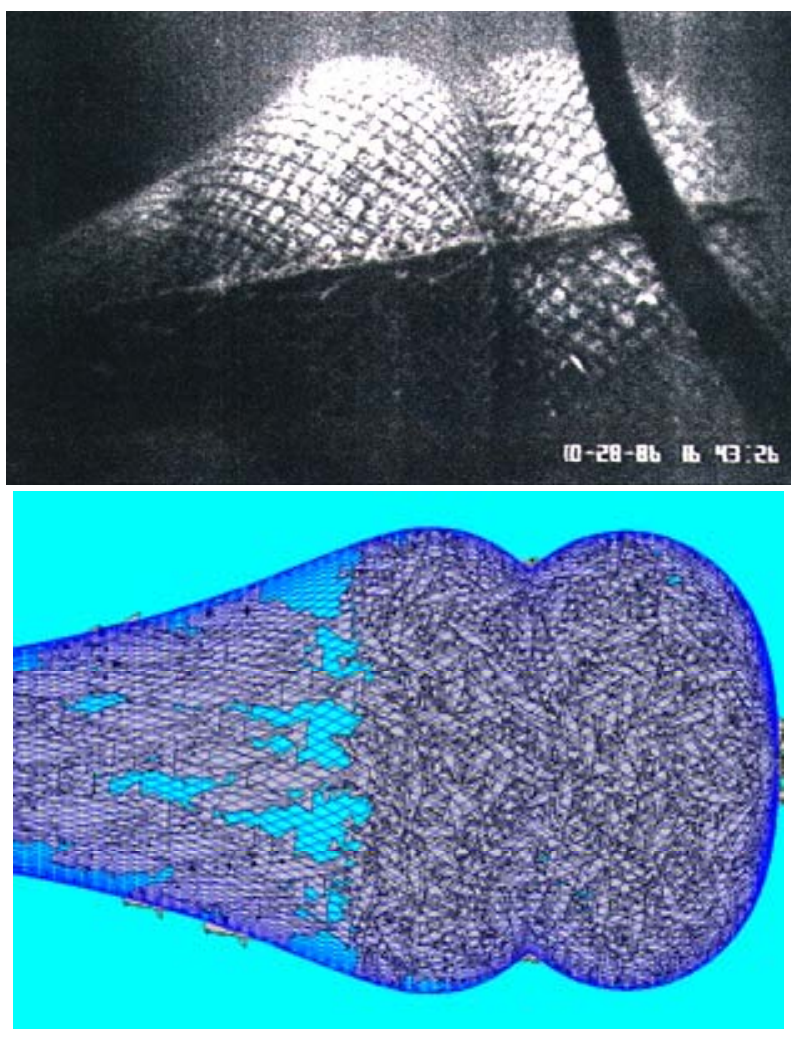

Fig. 1. Cod-end with round strap. Top: underwater photo. Bottom: simulation using FEMNET and PRESEMO tools 


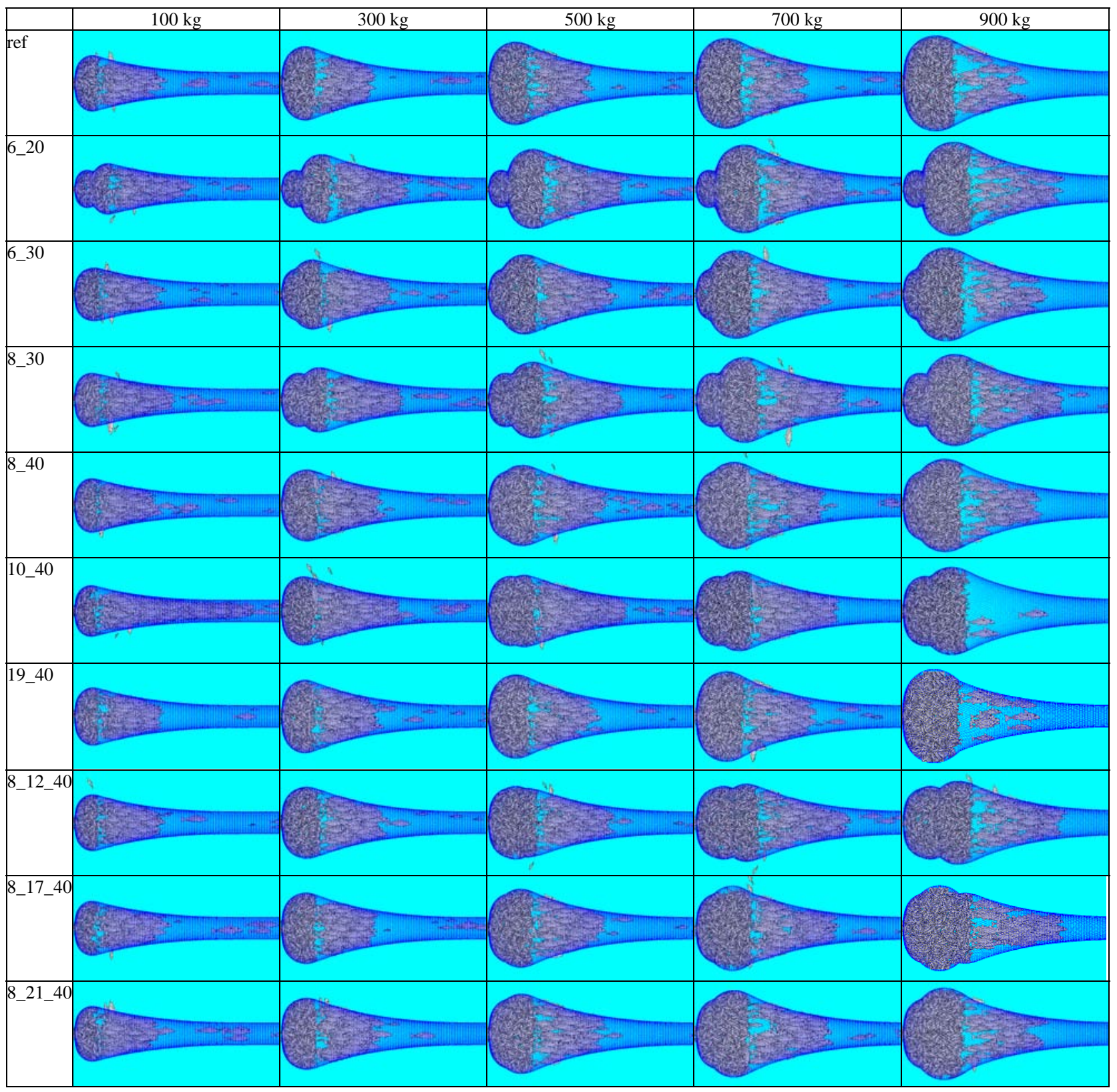




$$
\begin{aligned}
& \underline{\Xi} \\
& \underline{\equiv}
\end{aligned}
$$



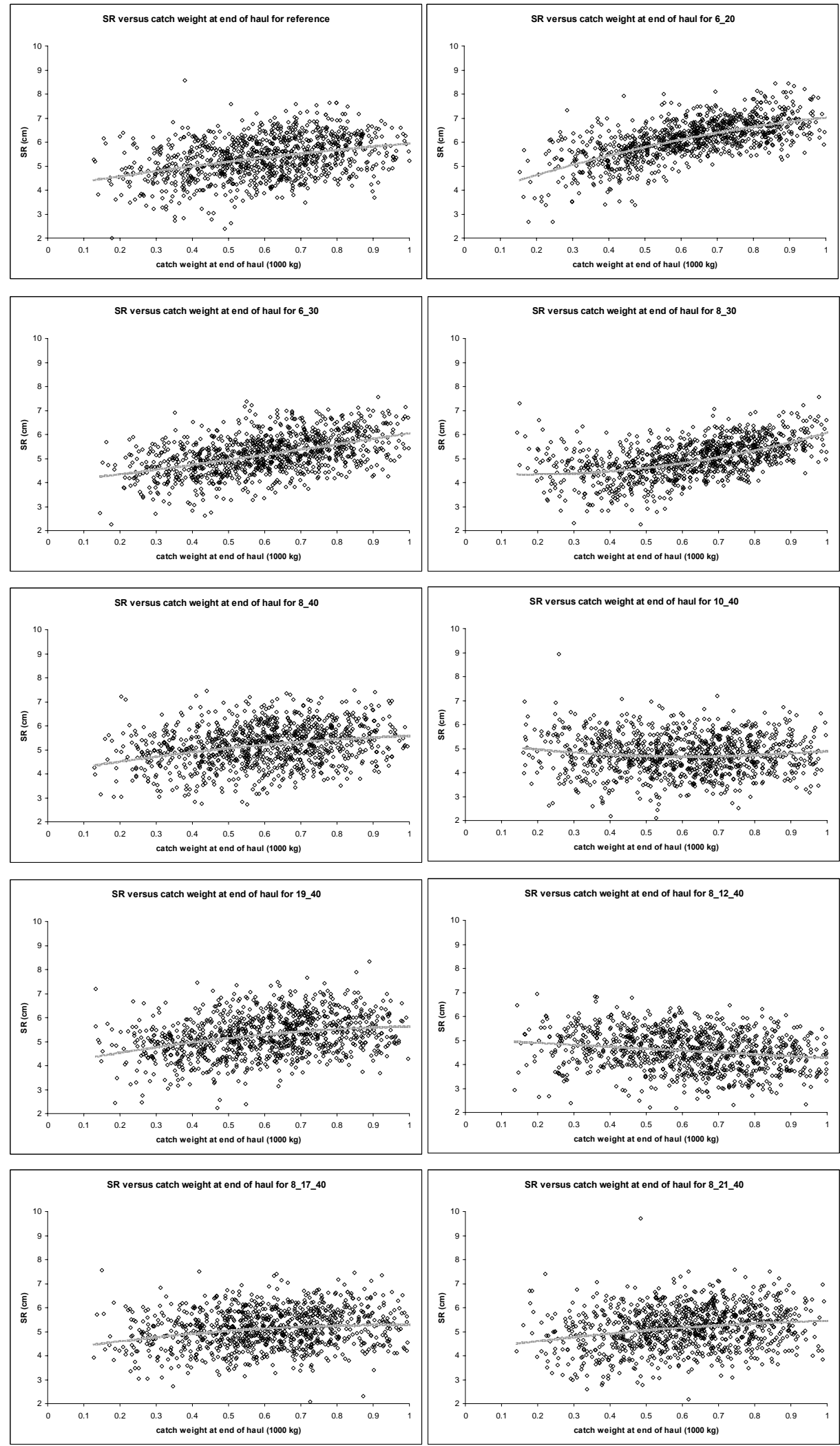

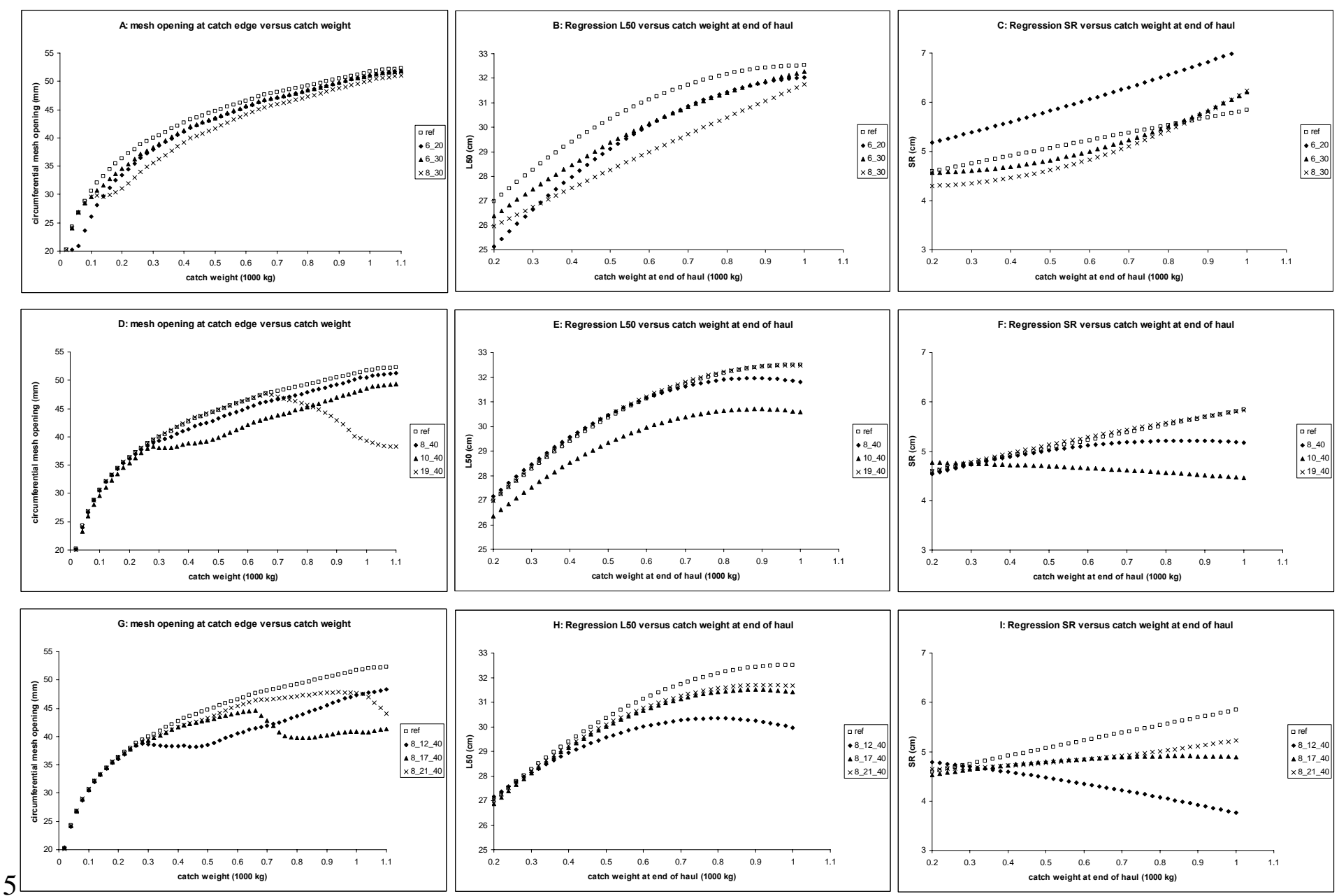


\section{Table 1: Basic cod-end data}

\begin{tabular}{ll}
\hline Mesh type & Diamond \\
Inner mesh size distribution & Normal \\
Mean inner mesh size $(\mathrm{mm})$ & 100 \\
Inner mesh size variance $\left(\mathrm{mm}^{2}\right)$ & 9 \\
Full mesh size $(\mathrm{mm})$ & 115 \\
Number of meshes lengthways & 50 \\
Number of circumference meshes & 100 \\
Twine thickness $(\mathrm{mm})$ & 4 \\
\hline
\end{tabular}

Table 2: Cod-end designs studied. The position of round straps is given in number of meshes from the codline. The strap length is given in percentage of the stretched circumference length of the cod-end. Cod-end designs that were affected by the round strap(s) and the reference cod-end are marked $(*)$.

\begin{tabular}{rrrl}
\hline Cod-end & $\begin{array}{c}\text { Position } \\
\text { strap 1 }\end{array}$ & $\begin{array}{l}\text { Position } \\
\text { strap 2 }\end{array}$ & $\begin{array}{l}\text { Strap } \\
\text { length } \\
(\%)\end{array}$ \\
\hline Reference* & none & none & non \\
3_40 & 3 & none & 40 \\
4_30 & 4 & none & 30 \\
4_40 & 4 & none & 40 \\
4_50 & 4 & none & 50 \\
6_20* & 6 & none & 20 \\
6_30* & 6 & none & 30 \\
$6 \_40$ & 6 & none & 40 \\
6_50 & 6 & none & 50 \\
6_60 & 6 & none & 60 \\
8_30* & 8 & none & 30 \\
8_40* & 8 & none & 40 \\
$8 \_50$ & 8 & none & 50 \\
10_40* & 10 & none & 40 \\
19_40* & 19 & none & 40 \\
8_12_40* & 8 & 12 & 40 \\
8_17_40* & 8 & 17 & 40 \\
8_21_40* & 8 & 21 & 40 \\
\hline
\end{tabular}


Table 3: Fish data used in simulations. *: The parameter is altered randomly between hauls within the indicated interval limits.

\begin{tabular}{|c|c|c|c|c|c|c|}
\hline & Population 1 & Population 2 & Population 3 & Population 4 & Population 5 & Population 6 \\
\hline Species & Haddock & Haddock & Haddock & By-catch & By-catch & By-catch \\
\hline Number & $50<->2000 *$ & $10<->1400 *$ & $10<->320 *$ & $70<->300 *$ & $70<->200 *$ & $50<->200 *$ \\
\hline Size of fish distribution & Normal & Normal & Normal & Normal & Normal & Normal \\
\hline Mean length (mm) & 160.0 & 298.0 & 500.0 & 240.0 & 290.0 & 500.0 \\
\hline Var length $\left(\mathrm{mm}^{2}\right)$ & 578.0 & 737.0 & 5561.0 & 1600.0 & 1200.0 & 1600.0 \\
\hline Height factor (dimensionless) & 0.1720 & 0.1720 & 0.1720 & 0.1750 & 0.1750 & 0.1750 \\
\hline Height var (dimensionless) & 0.000027 & 0.000027 & 0.000027 & 0.000011 & 0.000011 & 0.000011 \\
\hline Width factor (dimensionless) & 0.1030 & 0.1030 & 0.1030 & 0.1100 & 0.1100 & 0.1100 \\
\hline Width var (dimensionless) & 0.000010 & 0.00001 & 0.00001 & 0.000004 & 0.000004 & 0.000004 \\
\hline Condition factor $\left(\mathrm{g} / \mathrm{cm}^{3}\right)$ & 0.0109 & 0.0109 & 0.0109 & 0.0116 & 0.0116 & 0.0116 \\
\hline Condition var $\left(\mathrm{g}^{2} / \mathrm{cm}^{6}\right)$ & 0.0 & 0.0 & 0.0 & 0.0 & 0.0 & 0.0 \\
\hline Entry interval distribution & Random & Random & Random & Random & Random & Random \\
\hline Entry interval (\% of entry period) & $50<->100 *$ & $50<->100 *$ & $50<->100 *$ & $50<->100 *$ & $50<->100 *$ & $50<->100 *$ \\
\hline Entry period (minute) & 240 & 240 & 240 & 240 & 240 & 240 \\
\hline Time travel down distribution & Linear on length & Linear on length & Linear on length & Linear on length & Linear on length & Linear on length \\
\hline Time travel down par A (minute/mm) & 0.005 & 0.005 & 0.005 & 0.005 & 0.005 & 0.005 \\
\hline Time travel down par B (minute) & 0.0 & 0.0 & 0.0 & 0.0 & 0.0 & 0.0 \\
\hline Exhaustion time distribution & Linear on length & Linear on length & Linear on length & Linear on length & Linear on length & Linear on length \\
\hline Exhaustion time par A (minute/mm) & 0.1 & 0.1 & 0.1 & 0.1 & 0.1 & 0.1 \\
\hline Exhaustion time var par A (minute ${ }^{2}$ ) & 0.03 & 0.03 & 0.03 & 0.03 & 0.03 & 0.03 \\
\hline Time between distribution & Fixed & Fixed & Fixed & Fixed & Fixed & Fixed \\
\hline Time between (minute) & 1.0 & 1.0 & 1.0 & 1.0 & 1.0 & 1.0 \\
\hline Catch packing density (dimensionless) & 1.0 & 1.0 & 1.0 & 1.0 & 1.0 & 1.0 \\
\hline $\begin{array}{l}\text { In front of packing density } \\
\text { (dimensionless) }\end{array}$ & 0.5 & 0.5 & 0.5 & 0.5 & 0.5 & 0.5 \\
\hline
\end{tabular}

Table 4: Towing time and other settings used in simulations.

\begin{tabular}{ll}
\hline Towing time (minute) & 200 \\
Hauling time (minute) & 15.0 \\
Escapement model & Soft distortion \\
Catch weight break value $(\mathrm{kg})$ & 0.0 \\
Catch weight zero distortion $(\mathrm{kg})$ & 5.0 \\
Fore factor & 0.5 \\
Escapement during haul factor & 0.8 \\
Max distortion mesh opening & 0.15 \\
Simulated populations & $1,2,3,4,5,6$ \\
Target populations & $1,2,3$ \\
\hline
\end{tabular}


Table 5: Maximum catch weights (kg) where the cod-end shape is not affected by the round strap. '-‘ means never affected. The length is the percentage of the stretched circumference of the cod-end. Position is the position of the round strap in number of mesh rows from the cod-line.

\begin{tabular}{cccccc}
\hline Position / Length & $20 \%$ & $30 \%$ & $40 \%$ & $50 \%$ & $60 \%$ \\
\hline 3 & & & - & & \\
4 & & - & - & - & \\
6 & 19 & 72 & - & - & - \\
8 & & 112 & 272 & - & \\
10 & & & 272 & & \\
19 & & & 661 & \\
\hline
\end{tabular}

Table 6: Maximum catch weights $(\mathrm{kg})$ where the cod-end shape is not affected by a second round strap. The first round strap is positioned 8 meshes from the cod-line. The length of both straps is $40 \%$ of the stretched circumferential length of the cod-end.

\begin{tabular}{lccc}
\hline Catch weight (kg) & 272 & 424 & 661 \\
\hline Position of the second rope (no. meshes) & 12 & 17 & 21 \\
\hline
\end{tabular}

Table 7: Selectivity parameter regression results for catch weights between 200 and $1000 \mathrm{~kg}$.

\begin{tabular}{|c|c|c|c|c|c|c|c|c|c|c|c|c|c|c|c|c|c|c|c|c|}
\hline & \multicolumn{2}{|c|}{ Ref } & \multicolumn{2}{|c|}{ 6_20 } & \multicolumn{2}{|c|}{ 6_30 } & \multicolumn{2}{|c|}{ 8_30 } & \multicolumn{2}{|c|}{ 8_40 } & \multicolumn{2}{|c|}{ 10_40 } & \multicolumn{2}{|c|}{ 19_40 } & \multicolumn{2}{|c|}{ 8_12_40 } & \multicolumn{2}{|c|}{ 8_17_40 } & \multicolumn{2}{|c|}{ 8_21_40 } \\
\hline $\begin{array}{l}\text { Catch weight } \\
(1000 \mathrm{~kg})\end{array}$ & $\begin{array}{l}\begin{array}{l}\text { L50 } \\
(\mathrm{cm})\end{array} \\
\end{array}$ & $\begin{array}{l}\begin{array}{l}\text { SR } \\
(\mathrm{cm})\end{array} \\
\end{array}$ & $\begin{array}{l}\begin{array}{l}\text { L50 } \\
(\mathrm{cm})\end{array} \\
\end{array}$ & $\begin{array}{l}\begin{array}{l}\text { SR } \\
(\mathrm{cm})\end{array} \\
\end{array}$ & $\begin{array}{l}\begin{array}{l}\text { L50 } \\
(\mathrm{cm})\end{array} \\
\end{array}$ & $\begin{array}{l}\begin{array}{l}\text { SR } \\
(\mathrm{cm})\end{array} \\
\end{array}$ & $\begin{array}{l}\begin{array}{l}\text { L50 } \\
(\mathrm{cm})\end{array} \\
\end{array}$ & $\begin{array}{l}\begin{array}{l}\text { SR } \\
(\mathrm{cm})\end{array} \\
\end{array}$ & $\begin{array}{l}\begin{array}{l}\text { L50 } \\
(\mathrm{cm})\end{array} \\
\end{array}$ & $\begin{array}{l}\begin{array}{l}\text { SR } \\
(\mathrm{cm})\end{array} \\
\end{array}$ & $\begin{array}{l}\begin{array}{l}\text { L50 } \\
(\mathrm{cm})\end{array} \\
\end{array}$ & $\begin{array}{l}\begin{array}{l}\text { SR } \\
(\mathrm{cm})\end{array} \\
\end{array}$ & $\begin{array}{l}\begin{array}{l}\text { L50 } \\
(\mathrm{cm})\end{array} \\
\end{array}$ & $\begin{array}{l}\begin{array}{l}\text { SR } \\
(\mathrm{cm})\end{array} \\
\end{array}$ & $\begin{array}{l}\text { L50 } \\
(\mathrm{cm})\end{array}$ & $\begin{array}{l}\mathrm{SR} \\
(\mathrm{cm})\end{array}$ & $\begin{array}{l}\begin{array}{l}\text { L50 } \\
(\mathrm{cm})\end{array} \\
\end{array}$ & $\begin{array}{l}\begin{array}{l}\text { SR } \\
(\mathrm{cm})\end{array} \\
\end{array}$ & $\begin{array}{l}\text { L50 } \\
(\mathrm{cm})\end{array}$ & $\begin{array}{l}\mathrm{SR} \\
(\mathrm{cm})\end{array}$ \\
\hline 0.2 & 26.3 & 4.6 & 24.2 & 4.6 & 25.7 & 4.4 & 25.2 & 4.4 & 26.3 & 4.5 & 26.6 & 5.0 & 26.1 & 4.5 & 26.3 & 4.9 & 26.3 & 4.6 & 26.3 & 4.6 \\
\hline 0.3 & 27.7 & 4.8 & 25.7 & 5.1 & 26.9 & 4.5 & 26.1 & 4.4 & 27.6 & 4.7 & 27.5 & 4.9 & 27.5 & .8 & 27.4 & 4.8 & 27.6 & 4.8 & 27.5 & 4.8 \\
\hline 0.4 & 28.8 & 5.0 & 27.0 & 5.4 & 28.0 & 4.8 & 27.0 & 4.5 & 28.7 & 4.9 & 28.4 & 4.8 & 28.7 & 5.0 & 28.3 & 4.8 & 28.6 & 4.9 & 28.6 & 4.9 \\
\hline 0.5 & 29.9 & 5.2 & 28.1 & 5.8 & 29.0 & 5.0 & 27.9 & & 29.6 & & 29.1 & & 29.7 & 2 & 29.0 & 4.7 & 29.6 & 5.0 & 29.5 & 5.1 \\
\hline 0.6 & 30.7 & 5.4 & 29.1 & 6.1 & 29.8 & 5.2 & 28.7 & 4.8 & 30.4 & 5.2 & 29.7 & & 30.5 & 5.3 & 29.6 & 4.6 & 30.3 & 5.1 & 30.3 & 5.2 \\
\hline 0.7 & 31.4 & 5.5 & 30.0 & 6.4 & 30.6 & 5.4 & 29.4 & 5.1 & 31.0 & 5.3 & 30.2 & 4.7 & 31.2 & 5.4 & 30.1 & 4.5 & 30.9 & 5.2 & 30.9 & 5.3 \\
\hline 0.8 & 31.9 & 5.7 & 30.7 & 6.6 & 31.1 & 5.6 & 30.0 & 5.4 & 31.5 & 5.4 & 30.6 & 4.7 & 31.7 & 5.5 & 30.3 & 4.4 & 31.3 & 5.3 & 31.4 & 5.4 \\
\hline 0.9 & 32.2 & 5.8 & 31.3 & 6.9 & 31.6 & 5.8 & 30.6 & 5.7 & 31.8 & 5.5 & 30.8 & 4.8 & 32.0 & 5.6 & 30.5 & 4.4 & 31.6 & 5.3 & 31.7 & 5.4 \\
\hline 1.0 & 32.4 & 6.0 & 31.7 & 7.0 & 31.9 & 6.1 & 31.1 & 6.1 & 32.0 & 5.6 & 30.9 & 4.9 & 32.2 & 5.6 & 30.4 & 4.3 & 31.6 & 5.3 & 31.9 & 5.5 \\
\hline
\end{tabular}

